\title{
Primate social structure as a predictor of modes of communication and the ability to learn a human language
}

\section{Rebecca Jade Sullivan}

\begin{abstract}
For little over five decades, scientists have attempted to teach nonhuman hominids to communicate using human languages. The decision to utilise nonhuman hominids for this area of research is often attributed to their close genetic relatedness and similarly complex social structures to humans (Gardner and Gardner 1978). However, there has been minimal explanation in the literature as to why more complex social group structures allow for successful human language acquisition. Furthermore, there has been no investigation into whether other nonhominid primates, who may be more genetically dissimilar to humans but share similar social group complexity, could also be good candidates for human language acquisition. The following essay will argue that nonhuman hominids are likely successful at human language acquisition as a result of the social complexity hypothesis - a theory that states there is a positive association between social group and communication complexity (Freeberg et al. 2012). It will be proposed that the social complexity hypothesis may also be useful for identifying potential nonhominid candidates for future primate language acquisition research. However, future research should also analyse language acquisition in genera that do not appear to follow the social complexity hypothesis, to determine whether learning human languages requires only social complexity or communication complexity, and not both in combination.
\end{abstract}

\section{Keywords}

primate, social structure, social complexity hypothesis, language, great ape 


\section{Introduction}

The potential for nonhuman primates to learn human languages has both intrigued and baffled scientists for decades. Chimpanzees (Pan troglodytes) and gorillas (Gorilla gorilla) have often been the species of choice in studies of primate language acquisition, with researchers usually attributing this decision to both their close genetic relatedness to humans and the social complexity of the species (e.g. Gardner and Gardner 1969; Patterson 1978). However, there has been little explanation by researchers as to why social complexity in nonhuman hominids ${ }^{1}$ makes them suitable candidates for learning visual human languages, nor is there any indication in the literature as to why nonhominid primates ${ }^{2}$ with equal levels of social complexity are not chosen for these studies. According to the social complexity hypothesis, as social group styles increase in complexity, so too do the modes of communication (Freeberg et al. 2012). This mostly holds true in nonhuman hominids, with those species that have similarly complex social systems to humans also exhibiting highly complex methods of communication. For example, both chimpanzees and human hunter-gather societies form highly complex social groups, whereby a larger community will often temporarily split into smaller subgroups for various social benefits. As a result, complex forms of communication, such as gesturing and facial expressions, are required in order to communicate over long distances and re-establish relationships with other individuals when the groups reconvene (Dunbar 1993; Aureli et al. 2008). This relationship between social and communicative complexity offers a potential explanation for the exclusive use of hominid species in primate language acquisition research. However, nonhominid primate species with complex social groups may be equally receptive to learning human languages, and could be identified for future research opportunities based on the similarity of their social structures to that of humans. In turn, primate species that are socially dissimilar to humans could be identified as poor candidates for learning a human language through this method, as their modes of communication are predicted to be incompatible with human languages.

This essay aims to investigate the potential effectiveness of the social complexity hypothesis in predicting successful human language acquisition, by exploring the link between social complexity and communicative complexity in both

1 A primate family consisting of chimpanzees, bonobos, gorillas and orang-utans (i.e. great apes).

2 Any primate species that is not a great ape. 
human and nonhuman primates. Additionally, this essay aims to identify suitable and unsuitable candidate species for future language acquisition research in nonhuman primates.

\section{The differences between communication and language}

Before delving into the research question, an understanding of the relationship and differences between communication and language is needed. Primates use communication to relay a message, and this can occur in four forms. Olfactory communication relies on the use of chemical signals from scent gland excretions, saliva or mucus to relay information regarding female receptivity, territorial boundaries (Heymann 2006), dominance status (Roberts 2012) and mate attraction (Heymann 2006; Scordato and Drea 2007). Tactile communication is intimate, involving skin-to-skin contact such as allogrooming and embracing (Weber 1973) and is used to maintain social structure, strengthen bonds between individuals, relieve stress and social agitation and maintain mother-infant attachments (Hertenstein et al. 2006). Auditory communication can occur through vocalisations, as well as acoustic gestures such as tree buttress drumming (Arcadi et al. 1998), branch shaking (Zhao 1997), chest-beating or hand-clapping (Kalan and Rainey 2009), and is used to express social status (Remedios et al. 2009), defend territory, assist in agonistic confrontations and advertise alliances and group strength (Hagen and Hammerstein 2009). Finally, visual communication can involve the use of brachiomanual gestures such as arm-raising (Pollick and de Waal 2007) and beckoning (Hobaiter and Byrne 2011), facial expressions (Micheletta et al. 2015) and body language/posture (Smith and Delgado 2015) to convey messages about an individual's internal state such as emotions and desires (Pika et al. 2003; Parr et al. 2005).

Human language is a subcategory of communication, aligning with either auditory (i.e. speech) or visual (e.g. American Sign Language (ASL), or reading and writing) communication. While all primates are capable of communicating using sounds, human language is unique in that it is recursive, uses words and semantics and involves hierarchical syntax (Hauser et al. 2002; Berwick et al. 2013; Bolhuis et al. 2014). That is, there is an infinite combination of sentence structures and lengths in human language, producing limitless expressive power. 
While nonhuman primates naturally do not communicate using human-like language, a number of experiments have attempted to teach human languages to other hominid species. Early attempts to induce speech in chimpanzees and orang-utans (Pongo spp.) proved unsuccessful, due to morphological constraints of breathing control apparatus in the species only allowing for short, unmodulated utterances (Bryan 1963; Gardner and Gardner 1969; MacLarnon and Hewitt 1999). Subsequent research focused heavily on teaching nonhuman hominids to communicate using human visual languages, with greater success. Chimpanzees (e.g. Washoe and Nim Chimpsky), gorillas (e.g. Koko) and orang-utans (e.g. Chantek) have been taught over 100 signs in ASL (Gardner and Gardner 1969, 1978; Patterson 1978; Terrace et al. 1979; Miles 1990). Bonobos (Pan paniscus) such as Kanzi have also learned to read and communicate using hundreds of lexigrams - geometric symbols that function similarly to written language (Savage-Rumbaugh et al. 1985).

\section{The link between social structure and mode of communication}

The question remains: why are nonhuman hominid species successful at learning visual human languages like ASL and lexigrams? One of the most compelling and popular ideas, the social complexity hypothesis, suggests that complex social systems require complex modes of communication (Freeberg et al. 2012). With the exception of gorillas, all nonhuman hominids live in individual-based fission-fusion societies-one of the most complex social systems of any animal (van Schaik 1999; Ramos-Fernández 2005; Amrein et al. 2014; Bergman and Beehner 2015; Classen et al. 2016). These fissionfusion societies consist of large communities that often divide into smaller, temporary parties that provide various social benefits to in-group members, such as reducing in-group feeding competition and increasing the group's ability to defend territory (Lehmann et al. 2006). This social structure also requires animals to be able to mentally organise group members and their relationships, and to communicate over long distances in order to effectively coordinate group activities (van Schaik 1999; Aureli et al. 2008).

Modern hunter-gatherer humans often form similar fission-fusion groups, known as 'concentration-dispersal' social systems (Dunbar 1993; McComb and Semple 2005). This social system typically arises in environments where food and water availability are unpredictable. During periods of resource abundance, hunter-gatherer humans typically reside in small groups. 
However, during times of resource scarcity, these separate parties reassemble into a larger group, congregating at sites where resources are available for months at a time, such as a waterhole during the dry season (Dunbar 1993). Similar to fission-fusion societies, these highly flexible concentration-dispersal societies require hunter-gathers to be able to reassess relationships upon group reassembly, and maintain group cohesion over long distances (Dunbar 1993). As predicted by the social complexity hypothesis, human and nonhuman hominids also rely heavily on complex visual and auditory communication, including gestures, facial expressions and spoken language (Pika 2008). It thus stands to reason that other primate species with highly complex social systems should exhibit similar styles of complex communication to hominids, and thus may also be able to learn human languages.

A number of primate studies have supported the social complexity hypothesis, finding that group size is an effective predictor of both auditory and tactile modes of communication. A meta-analysis of 42 primate species by McComb and Semple (2005) found that as average group size and time spent allogrooming increases, so too does vocal repertoire size. Because of these relationships, a number of studies have suggested that vocal complexity may have facilitated the evolution of human language, serving as a way of maintaining social bonds and group cohesion between multiple individuals simultaneously when group size became too large for one-on-one allogrooming to serve this purpose (Dunbar 1993; Freeberg et al. 2012). Thus, while primates may not be able to physically speak a human language, this hypothesis still suggests that primates that live in large, complex societies could be good candidates for at least understanding spoken human languages.

Research has also found a positive correlation between visual communication and group complexity. A meta-analysis of 12 haplorrhine primate species by Dobson (2009) found that as group size increases, facial expressions become more complex and occur more frequently. While no research has been conducted on the relationship between gestural communication and social complexity in primates, it could also be predicted that more complex social structures should increase gestural complexity and use. Because ASL and lexigrams are visual and gestural modes of communication, primate species that rely more on these modes of communication as a result of more complex social structures should be ideal candidates for both understanding and communicating using human languages. 


\section{Other primate candidates for learning human languages}

Based on the similarities between social structure and associated modes of communication, there are a number of other primate species that could also be capable of learning human languages. Some of the most likely candidates are Old World monkeys from the Macaca genus, such as barbary macaques (M. sylvanus), pigtailed macaques ( $M$. nemestrina) and rhesus macaques (M. mulatta). All three species live in multimale-multifemale social groups of similar complexity and size to that of chimpanzees, bonobos and humans (McComb and Semple 2005; Burrows et al. 2009; Grueter et al. 2013). Like hominids, facial expression in macaques is highly complex and an integral part of communication (Burrows 2008). Additionally, all three species often use visual gestural communication, which is correlated with socially complex behaviours such as dominance hierarchies and social bonding (Maestripieri 2007).

However, other primate species who do not appear to fit the parameters of the hypothesis are also potential candidates for human language studies, bringing into question the effectiveness of the social complexity hypothesis in predicting language acquisition in nonhuman primates. Spider monkeys (Ateles spp.), for example, live in complex fission-fusion societies, and while there is some evidence of facial expression and gesturing, overall their visual communication is not as complex as that of hominids and macaques (RamosFernández 2005; Schaffner and Aureli 2005). Gibbons (Hylobates spp.), on the other hand, are socially monogamous - an arguably simpler social system than that of hominid and groups of Macaca, according to the social complexity hypothesis (Freeberg et al. 2012). Yet, they display highly complex gestural and facial expression in communication (Liebal et al. 2004; Scheider et al. 2014). Gorillas live in semicomplex polygynous societies but have complex facial expression and gestural communication, and are still able to learn human language (Dobson 2009; Freeberg et al. 2012). This suggests that highly complex social structures may not be the most important contributing factor towards language acquisition. Therefore, it is particularly important to study spider monkeys, gibbons and gorillas to determine whether social complexity and complex communication are both required to learn a human language, or whether close genetic relatedness to humans is the main determinant of a species' ability to learn a human language. 
Using the social complexity hypothesis, it could be predicted that species that are highly socially dissimilar to hominids are unlikely to be able to learn a human language. For instance, nocturnal and solitary strepsirrhines such as the grey mouse lemur (Microcebus murinus; Eberle and Kappeler 2008), the aye-aye (Daubentonia madagascariensis; Sterling and McCreless 2007), and all lorisiformes (Kawamura and Kubotera 2004) rely heavily on olfaction to communicate with other individuals (del Barco-Trillo et al. 2011). In general, strepsirrhines also have far less complex visual communication systems than other primates due to poor visibility at night, limited interaction with other individuals and a fused upper lip disallowing facial expression (Kappeler 2012; Kemp and Kaplan 2013). Within the haplorrhine suborder, nocturnal tarsiformes are more gregarious than most nocturnal strepsirrhines; hence, visual and auditory communication such as facial expressions and vocalisations are somewhat more complex (MacKinnon and MacKinnon 1980). However, these are not as complex as the visual and auditory forms of communication found in hominids or macaques. As humans rely mostly on verbalisation, gestures and facial expressions to communicate, neither strepsirrhines nor tarsiformes would be suitable candidates for learning a human language.

\section{Conclusion}

Research has repeatedly affirmed the social complexity hypothesis, which states that complex social structure is correlated with more complex modes of communication, such as elaborate gestural systems, facial expressions and vocal repertoire. Based on this hypothesis, it can be predicted that nonhuman hominids are able to learn human languages because they share social systems that are similar in complexity and style to humans. However, other nonhominid species with equally complex social systems, such as some species of macaque, could also be excellent candidates for learning human languages. Future research should focus on language acquisition in nonhominid primates living in fission-fusion societies, to determine whether they share the same ability as hominids to learn human languages. In addition, research into species that do not appear to follow the social complexity hypothesis could provide insight into whether human language acquisition requires both social and communicative complexity, just one of these factors, or simply close genetic relatedness to humans. 


\section{Acknowledgements}

I would like to express my sincerest thanks to Dr Alison Behie and Rebecca Hendershott for their continued support, guidance and patience throughout the process of writing this essay. I would also like to thank my partner Chinmoy for his unwavering optimism, encouragement and proofreading efforts; and without whom this essay would not have been possible.

\section{References}

Amrein M, Heistermann M, Weingrill T. 2014. The effect of fission-fusion zoo housing on hormonal and behavioral indicators of stress in Bornean orangutans (Pongo pygmaeus). Int J Primatol. 35(2):509-528. doi.org/ 10.1007/s10764-014-9765-5

Arcadi AC, Robert D, Boesch C. 1998. Buttress drumming by wild chimpanzees: Temporal patterning, phrase integration into loud calls, and preliminary evidence for individual distinctiveness. Primates. 39(4):505-518. doi.org/10.1007/BF02557572

Aureli F, Schaffner CM, Boesch C, Bearder SK, Call J, Chapman CA, Connor R, Di Fiore A, Dunbar RI, Henzi SP. 2008. Fission-fusion dynamics: New research frameworks. Curr Anthropol. 49(4):627-654. doi.org/10.1086/586708

Bergman TJ, Beehner JC. 2015. Measuring social complexity. Anim Behav. 103:203-209. doi.org/10.1016/j.anbehav.2015.02.018

Berwick RC, Friederici AD, Chomsky N, Bolhuis JJ. 2013. Evolution, brain, and the nature of language. Trends Cogn Sci. 17(2):89-98. doi.org/ 10.1016/j.tics.2012.12.002

Bolhuis JJ, Tattersall I, Chomsky N, Berwick RC. 2014. How could language have evolved? PLoS Biol 12(8):e1001934. doi.org/10.1371/journal. pbio. 1001934

Bryan AL. 1963. The essential morphological basis for human culture. Curr Anthropol. 4(3):297-306. doi.org/10.1086/200377 
Burrows AM. 2008. The facial expression musculature in primates and its evolutionary significance. BioEssays. 30(3):212-225. doi.org/10.1002/ bies.20719

Burrows AM, Waller BM, Parr LA. 2009. Facial musculature in the rhesus macaque (Macaca mulatta): Evolutionary and functional contexts with comparisons to chimpanzees and humans. J Anat. 215(3):320-334. doi.org/10.1111/j.1469-7580.2009.01113.x

Classen D, Kiessling S, Mangalam M, Kaumanns W, Singh M. 2016. Fissionfusion species under restricted living conditions: A comparative study of dyadic interactions and physical proximity in captive bonobos and Bornean orangutans. Curr Sci. 110(5):839-850.

del Barco-Trillo J, Burkert B, Goodwin T, Drea C. 2011. Night and day: The comparative study of strepsirrhine primates reveals socioecological and phylogenetic patterns in olfactory signals. J Evol Biol. 24(1):82-98. doi.org/10.1111/j.1420-9101.2010.02145.x

Dobson SD. 2009. Socioecological correlates of facial mobility in nonhuman anthropoids. Am J Phys Anthropol. 139(3):413-420. doi.org/10.1002/ ajpa. 21007

Dunbar RI. 1993. Coevolution of neocortical size, group size and language in humans. Behav Brain Sci. 16(04):681-694. doi.org/10.1017/ S0140525X00032325

Eberle M, Kappeler PM. 2008. Mutualism, reciprocity, or kin selection? Cooperative rescue of a conspecific from a boa in a nocturnal solitary forager the gray mouse lemur. Am J Primatol. 70(4):410-414. doi.org/ 10.1002/ajp.20496

Freeberg TM, Dunbar RI, Ord TJ. 2012. Social complexity as a proximate and ultimate factor in communicative complexity. Philos Trans R Soc Lond B Biol Sci. 367(1597):1785-1801. doi.org/10.1098/rstb.2011.0213

Gardner RA, Gardner BT. 1969. Teaching sign language to a chimpanzee. Science 165(3894):664-672. doi.org/10.1126/science.165.3894.664

Gardner RA, Gardner BT. 1978. Comparative psychology and language acquisition. Ann N Y Acad Sci. 309(1):37-76. doi.org/10.1111/j.17496632.1978.tb29441.x 
Grueter CC, Bissonnette A, Isler K, van Schaik CP. 2013. Grooming and group cohesion in primates: Implications for the evolution of language. Evol Hum Behav. 34(1):61-68. doi.org/10.1016/j.evolhumbehav.2012.09.004

Hagen EH, Hammerstein P. 2009. Did Neanderthals and other early humans sing? Seeking the biological roots of music in the territorial advertisements of primates, lions, hyenas, and wolves. Music Sci. 13(2):291-320. doi. org/10.1177/1029864909013002131

Hauser MD, Chomsky N, Fitch WT. 2002. The faculty of language: What is it, who has it, and how did it evolve? Science. 298(5598):1569-1579. doi.org/10.1126/science.298.5598.1569

Hertenstein MJ, Verkamp JM, Kerestes AM, Holmes RM. 2006. The communicative functions of touch in humans, nonhuman primates, and rats: A review and synthesis of the empirical research. Genet Soc Gen Psychol Monogr. 132(1):5-94. doi.org/10.3200/MONO.132.1.5-94

Heymann EW. 2006. Scent marking strategies of New World primates. Am J Primatol. 68(6):650-661. doi.org/10.1002/ajp.20258

Hobaiter C, Byrne RW. 2011. The gestural repertoire of the wild chimpanzee. Anim Cogn. 14(5):745-767. doi.org/10.1007/s10071-011-0409-2

Kalan AK, Rainey HJ. 2009. Hand-clapping as a communicative gesture by wild female swamp gorillas. Primates. 50(3):273-275. doi.org/10.1007/ s10329-009-0130-9

Kappeler PM. 2012. Behavioral ecology of strepsirrhines and tarsiers. In: JC Mitani, J Call, PM Kappeler, RA Palombit, JB Silk, editors. The evolution of primate societies. Chicago (IL): University of Chicago Press. pp. 17-42.

Kawamura S, Kubotera N. 2004. Ancestral loss of short wave-sensitive cone visual pigment in lorisiform prosimians, contrasting with its strict conservation in other prosimians. J Mol Evol. 58(3):314-321. doi.org/ $10.1007 / \mathrm{s} 00239-003-2553-\mathrm{z}$

Kemp C, Kaplan G. 2013. Facial expressions in common marmosets (Callithrix jacchus) and their use by conspecifics. Anim Cogn. 16(5):773788. doi.org/10.1007/s10071-013-0611-5 
Lehmann J, Korstjens AH, Dunbar R. 2006. Fission-fusion social systems as a strategy for coping with ecological constraints: A primate case. Evol Ecol. 21(5):613-634. doi.org/10.1007/s10682-006-9141-9

Liebal K, Pika S, Tomasello M. 2004. Social communication in siamangs (Symphalangus syndactylus): Use of gestures and facial expressions. Primates. 45(1):41-57. doi.org/10.1007/s10329-003-0063-7

MacKinnon J, MacKinnon K. 1980. The behavior of wild spectral tarsiers. Int J Primatol. 1(4):361-379. doi.org/10.1007/BF02692280

MacLarnon AM, Hewitt GP. 1999. The evolution of human speech: The role of enhanced breathing control. Am J Phys Anthropol. 109(3): 341-363. doi.org/10.1002/(SICI)1096-8644(199907)109:3<341::AIDAJPA5 $>3.0 . C O ; 2-2$

Maestripieri D. 2007. Gestural communication in three species of macaques (Macaca mulatta, M. nemestrina, $M$. arctoides): Use of signals in relation to dominance and social context. In: K Liebal, C Muller, S Pika, editors. Gestural communication in nonhuman and human primates. Amsterdam (Netherlands): John Benjamins Publishing Company. pp. 51-66. doi.org/ 10.1075/bct.10.06mae

McComb K, Semple S. 2005. Coevolution of vocal communication and sociality in primates. Biol Lett. 1(4):381-385. doi.org/10.1098/ rsbl.2005.0366

Micheletta J, Whitehouse J, Parr LA, Waller BM. 2015. Facial expression recognition in crested macaques (Macaca nigra). Anim Cogn. 18(4):985990. doi.org/10.1007/s10071-015-0867-z

Miles H. 1990. The cognitive foundations for reference in a signing orangutan. In: ST Parker, KR Gibson, editors. 'Language' and intelligence in monkeys and apes: Comparative developmental perspectives. New York (NY): Cambridge University Press. pp. 511-539. doi.org/10.1017/ CBO9780511665486.021

Parr LA, Waller BM, Fugate J. 2005. Emotional communication in primates: Implications for neurobiology. Curr Opin Neurobiol. 15(6):716-720. doi.org/10.1016/j.conb.2005.10.017 
Patterson FG. 1978. The gestures of a gorilla: Language acquisition in another pongid. Brain Lang. 5(1):72-97. doi.org/10.1016/0093-934X (78)90008-1

Pika S. 2008. Gestures of apes and pre-linguistic human children: Similar or different? First Lang. 28(2):116-140. doi.org/ $10.1177 / 0142723707080966$

Pika S, Liebal K, Tomasello M. 2003. Gestural communication in young gorillas (Gorilla gorilla): Gestural repertoire, learning, and use. Am J Primatol. 60(3):95-111. doi.org/10.1002/ajp.10097

Pollick AS, de Waal FB. 2007. Ape gestures and language evolution. Proc Natl Acad Sci. 104(19):8184-8189. doi.org/10.1073/pnas.0702624104

Ramos-Fernández G. 2005. Vocal communication in a fission-fusion society: Do spider monkeys stay in touch with close associates? Int J Primatol. 26(5):1077-1092. doi.org/10.1007/s10764-005-6459-z

Remedios R, Logothetis NK, Kayser C. 2009. Monkey drumming reveals common networks for perceiving vocal and nonvocal communication sounds. Proc Natl Acad Sci. 106(42):18010-18015. doi.org/10.1073/ pnas.0909756106

Roberts SC. 2012. On the relationship between scent-marking and territoriality in callitrichid primates. Int J Primatol. 33(4):749-761. doi.org/10.1007/s10764-012-9604-5

Savage-Rumbaugh S, Rumbaugh DM, McDonald K. 1985. Language learning in two species of apes. Neurosci Biobehav Rev. 9(4):653-665. doi.org/10.1016/0149-7634(85)90012-0

Schaffner CM, Aureli F. 2005. Embraces and grooming in captive spider monkeys. Int J Primatol. 26(5):1093-1106. doi.org/10.1007/s10764005-6460-6

Scheider L, Liebal K, Oña L, Burrows A, Waller B. 2014. A comparison of facial expression properties in five hylobatid species. Am J Primatol. 76(7):618-628. doi.org/10.1002/ajp.22255

Scordato ES, Drea CM. 2007. Scents and sensibility: Information content of olfactory signals in the ringtailed lemur, Lemur catta. Anim Behav. 73(2):301-314. doi.org/10.1016/j.anbehav.2006.08.006 
Smith LW, Delgado RA. 2015. Body language: The interplay between positional behavior and gestural signaling in the genus Pan and its implications for language evolution. Am J Phys Anthropol. 157(4):592602. doi.org/10.1002/ajpa.22751

Sterling EJ, McCreless EE. 2007. Adaptations in the aye-aye: A review. In: L Gould, ML Sauther, editors. Lemurs: Ecology and Adaptation. New York (NY): Springer Publishing. pp. 159-184. doi.org/10.1007/978-0387-34586-4_8

Terrace HS, Petitto LA, Sanders RJ, Bever TG. 1979. Can an ape create a sentence. Science. 206(4421):891-902. doi.org/10.1126/science.504995

van Schaik CP. 1999. The socioecology of fission-fusion sociality in orangutans. Primates. 40(1):69-86. doi.org/10.1007/BF02557703

Weber I. 1973. Tactile communication among free-ranging langurs. Am J Phys Anthropol. 38(2):481-486. doi.org/10.1002/ajpa.1330380251

Zhao QK. 1997. Intergroup interactions in Tibetan macaques at Mt. Emei, China. Am J Phys Anthropol. 104(4):459-470. doi.org/10.1002/ (SICI) 1096-8644(199712)104:4<459::AID-AJPA3>3.0.CO;2-N 
This text is taken from the The Human Voyage: Undergraduate Research in Biological Anthropology: Volume 1, 2017, edited by Alison Behie, published 2017 by ANU eView, The Australian National University, Canberra, Australia.

dx.doi.org/10.22459/HV.01.2017.06 